\title{
Akronim dalam Komunitas Motor di Kota Merauke
}

\author{
Margaretha F. Narahawari \\ Fridanara06@gmail.com \\ Jenny Pakasi \\ Leika Kalangi \\ Universitas Sam Ratulangi
}

\begin{abstract}
This research will identify, classify, and analyze based on the phenomena of words formation. The data has been collected from some interviews of the motorcycle community members. Theories used in this research by Sampurno and Finoza.

The results of this research shows that the acronym used exclusively in the motorcycle community. According to the form of an acronym, there are four forms, namely: form initial characters of the word, syllable form, form initial character of the word and syllable, phrases form. And to the function in this research that acronym as a shorthand phrase or name, slogan or humor, distinguishing origin of a words and meaning.

Keywords: acronym, form, function, community
\end{abstract}

\section{Pendahuluan}

Bahasa merupakan alat komunikasi yang digunakan antar msyarakat, sehingga mayarakat merupakan penutur bahasa yang beragam. Keberagaman bahasa disebabkan oleh perkembangan masyarakat di berbagai aspek kehidupan, salah satunya perkembangan dalam pergaulan dalam setiap komunitas yang berbeda-beda. Hal tersebut menunjukkan bahwa semakin modern suatu bangsa dan kehidupannya, maka akan semakin berkembang pula bahasanya.

Pentingnya bahasa bagi manusia tidak perlu diragukan lagi. Hal itu tidak saja dibuktikan dengan menunjuk pemakaian bahasa dalam kehidupan sehari-hari, tetapi juga dapat dibuktikan dengan banyaknya perhatian para ilmuwan dan praktisi terhadap bahasa. Bahasa sebagai objek ilmu bukan monopoli para ahli bahasa. Para ilmuwan dalam bidang lain pun menjadikan bahasa sebagai objek studi karena mereka memerlukan bahasa sebagai alat bantu untuk mengomunikasikan berbagai hal (Finoza, 2002 :1).Bahasa yang kita gunakan dalam kehidupan sehari-hari dapat di kaji karena bahasa merupakan bagian dari linguistik. 
Linguistik merupakan ilmu atau studi tentang bahasa. Pernyataan tersebut sejalan dengan Uhlenbeck (1982:5) yang mengatakan studi bahasa adalah untuk memperoleh pengertian yang selengkapnya tentang gejala bahasa secara umum. Hal seperti ini dapat dicapai dengan penelitian dalam berbagai bahasa, yakni penelitian bentuk-bentuk kata. Penyelidikan bahasa selalu berarti kajian pemakaian bahasa dalam suatu masyarakat atau komunitas tertentu. Dalam bidang linguistik yang berhubungan dengan bentuk kata merupakan salah satu bagian dari bidang studi morfologi.

Morfologi adalah cabang linguistik yang mengidentifikasi satuan-satuan dasar bahasa sebagai satuan gramatikal. Morfologi mempelajari seluk-beluk bentuk kata serta pengaruh perubahan-perubahan bentuk kata serta fungsi perubahan-perubahan bentuk kata itu, baik fungsi gramatika maupun fungsi semantik. Pembentukan kata sendiri merupakan proses untuk menghasilkan kata-kata baru. Kata-kata dapat dibentuk melalui proses yang disebut proses morfologi. Proses ini meliputi: afiksasi, suppletion, reduplication, compounding, internal change dan derivation. Selain pembentukan-pembentukan kata tersebut, ada juga pola pembentukan lain yang disebut kreasi kata (O'Grady 1992: 133135), seperti conversion, clipping, blending, back formation, acronyms, coinage, morphological misanalysis, proper names. Berdasarkan uraian tersebut akronim merupan bagian dari pembentukan kata.

Akronim adalah proses pemendekan yang menggabungkan huruf atau suku kata atau bagian lain yang ditulis dan dilafalkan sebagai sebuah kata yang sedikit banyak memenuhi kaidah fonotaktik Indonesia (Parsidi, 1992:6). Sejalan dengan itu, Finoza (1993:32) juga mengemukakan bahwa akronim adalah singkatan yang berupa gabungan huruf awal, gabungan suku kata, ataupun huruf dan suku kata dari deret kata yang disingkat.

Berkaitan dengan pemanfaatan penyingkatan kata dalam komunikasi baik secara lisan maupun tulisan, penggunaan kosakata tertentu baik berbentuk istilah atau penyingkatan kata sudah bukan sesuatu yang asing, sehingga alasan memilih akronim dilatarbelakangi oleh tingginya produktivitas penggunaan akronim di kalangan masyarakat penggunaan bahasa, terutama dalam salah satu komunitas motor di kota Merauke. Pemilihan komunitas motor di kota Merauke dikarenakan beberapa komunitas tersebut mulai bermunculan di kota Merauke dan mempunyai istilah berupa akronim dan jarang diketahui oleh orang banyak ataupun komunitas motor lainnya.

Komunitas motor merupakan perkumpulan orang yang memiliki kegemaran yang sama dalam mengendarai motor untuk perjalanan jarak jauh, memodifikasi motor, ataupun 
salin bertukar pikiran untuk berkembangnya komunitas motor. Namun tidak terbatas pada satu jenis kendaraan atau motor apapun seperti tipe motor, merk motor, dapat bergabung ke dalam komunitas ini.

Sama halnya dalam berbahasa, bahasa yang digunakan setiap harinya di kota Merauke adalah bahasa Melayu Papua. Bahasa Melayu Papua merupakan sebuah bahasa yang dituturkan oleh penduduk Papua maupun penduduk non Papua yang sudah tinggal dan menetap di Papua. Kota Merauke sendiri merupakan salah satu dari 29 kota yang ada di Provinsi Papua dan terletak dibagian selatan yang memiliki wilayah terluas diantara kota di provinsi Papua.

\section{Perumusan Masalah}

Berdasarkan uraian di atas, maka perumusan masalah dalam penelitian ini:

1. Bentuk dan makna akronim apa saja dalam komunitas motor di kota Merauke?

2. Fungsi akronim apa saja dalam komunitas motor di kota Merauke?

\section{Tujuan Penelitian}

Penelitan ini bertujuan untuk:

1. Mengidentifikasi, mendeskripsikan, dan menganalisis bentuk dan makna akronim dalam komunitas motor di kota Merauke.

2. Mengidentifikasi, mendeskripsikan, dan menganalisis fungsi akronim dalam komunitas motor di kota Merauke.

\section{Manfaat Penelitian}

Manfaat dari penelitian ini terbagi dua, yaitu manfaat teoretis dan praktis

1. Manfaat teoretis, penelitian ini dapat menjadi referensi bagi perkembangan ilmu morfologi dan menambah kajian ilmu morfologi tentang bentuk kata, terlebih khusus untuk mengetahui teori dari bentuk, makna, dan fungsi, akronim.

2. Manfaat praktis, bagi komunitas tersebut atau orang-orang yang terkait agar dapat menciptakan istilah-istilah dengan menggunakan bentuk akronim yang dapat dipahami oleh masyarakat sekitar serta sesuai dengan kaidah abreviasi yang sudah ditentukan. 
3.

\section{Tinjauan Pustaka}

Nanda (2013) mengkaji Abreviasi, Afiksasi, dan Reduplikasi Ragam Bahasa Remaja dalam Media Sosial Facebook. Ia menjelaskan tentang abreviasi, afiksasi dan reduplikasi dalam ragam bahasa remaja di media sosial facebook dan faktor yang memengaruhi penggunaan abreviasi, afiksasi, dan reduplikasi dalam ragam bahasa remaja di media sosial facebook. Dalam penelitiannya menggunakan metode deskriptif kualitatif, data dikumpulkan dan disajikan dalam bentuk kata-kata. Penelitian ini memberikan kontribusi yang sangat besar bagi penulis dalam hal pemahaman secara lebih jelas tentang perbedaan abreviasi, afiksasi dan reduplikasi.

Wulandari (2013) mengkaji Penggunaan Abreviasi dalam Bahasa Sunda (Kajian Morfosemantik). Ia memaparkan kajian empat bentuk abreviasi, yaitu singkatan, penggalan, akronim, dan kontraksi dalam bahasa Sunda yang digunakan oleh masyarakat di kehidupan sehari-harinya dan memiliki keunikan tersendiri serta memaparkan perubahan makna yang terjadi. Penelitian ini menggunakan teori morfosemantik sebagai payung penelitian sehingga menambah referensi penulis tentang teori morfologi dan semantik.

Noviatri dan Reniwati (2015) mengkaji bentuk-bentuk abreviasi, yaitu singkatan dan akronim yang digunakan dalam surat kabar dan menjelaskan proses pembentukannya. Teori yang digunakan adalah teori abreviasi dan proses pembentukannya yang dikemukakan oleh Kridalaksana (2010) yang membagi abreviasi atas lima bentuk, yaitu: 1) singkatan, 2) akronim, 3) pemenggalan, 4) konstrkasi, dan 5) lambang huruf.

Hubungan tinjauan pustaka di atas dengan penelitian ini adalah penelitian ini hanya mengkaji bentuk dan makna akronim, serta fungsi dari akronim dalam sebuah komunitas motor yang menjadi objek dari penelitian ini.

\section{Landasan Teori}

\section{Akronim}

Istilah akronim adalah singkatan yang berupa gabungan huruf awal kata, gabungan suku kata, ataupun gabungan dan suku kata dari deret kata yang disingkat (Finoza, 
1993:32). Misalnya mayjen adalah mayor jenderal, rudal adalah peluru kendali, dan sidak adalah inspeksi mendadak. Mengakronimkan berarti membuat akronim atau menjadikan bentuk akronim. Pada bagian lain istilah akronim diartikan sebagai singkatan yang berupa gabungan huruf awal, gabungan suku kata, ataupun gabungan yang huruf dan suku kata dari deret yang disingkat.

Pengertian yang lain dikemukakan oleh Kridalaksana (dalam Sampurno, 1995:250) tentang istilah akronim, yaitu kependekan yang berupa gabungan huruf atau suku kata atau bagian lain yang ditulis dan dilafalkan sebagai kata yang wajar. Lebih dalam pembahasan itu disertai contoh sebagaimana berikut : Rudal (peluru kendali), Sonar (sound navigation ranging), Radar (radio detecting and ranging), dll.

Sementara Husain (1995:20) juga menyatakan istilah akronim dengan redaksi yang sama, yaitu singkatan yang berupa gabungan huruf awal, gabungan suku kata, ataupun gabungan huruf dan suku kata dari deret kata yang diperlakukan sebagai kata. Dari definisi tersebut dapat disimpulkan bahwa akronim merupakan salah satu jenis singkatan. Namun tidak semua singkatan disebut akronim, karena akronim dapat dibaca seperti kata pada umumnya.

\section{Bentuk-bentuk akronim}

Sebagaimana bentuk akronim yang sudah dipaparkan pada bagian sebelumnya, bentuk akronim menurut Tarigan (1993:172) dapat dibedakan menjadi tiga macam yaitu:

1. Akronim dari huruf awal kata, misalnya ABRI (Angkatan Bersenjata Republik Indonesia)

2. Akronim dari suku kata atau penggalan kata, misalnya SUPERSEMAR (Surat Perintah Sebelas Maret), Mendikbud (Menteri Pendidikan dan Kebudayaan), dan sebagainya

3. Akronim dari huruf awal kata dan suku kata atau penggalan kata, misalnya Akabri (Akademi Bersenjata Republik Indonesia), KORPRI (Korp Pegawai republik Indonesia), dan sebagainya.

Selain itu juga Finoza (1993:34) menjelaskan beberapa bentuk-bentuk akronim adalah sebagai berikut: 
a. Akronim nama diri yang berupa gabungan huruf awal dari deret kata yang disingkat, ditulis seluruhnya dengan huruf kapital. Misalnya:

- FISIP : Fakultas Ilmu Sosial dan Ilmu Politik

- $\quad$ KONI : Komite Olahraga Nasional Indonesia

b. Akronim nama diri yang berupa gabungan suku kata atau gabungan huruf dan suku kata dari deret kata, huruf awalnya ditulis dengan huruf kapital dan tidak diakhiri oleh tanda titik. Misalnya:

- Bappenas : Badan Perencanaan Pembangunan Nasional

- Sespa : Sekolah Staf dan Pemimpin Administrasi

c. Akronim yang bukan nama diri yang berupa gabungan huruf, suku kata, ataupun gabungan huruf dan suku kata dari deret kata yang disingkat, seluruhnya ditulis dengan huruf kecil dan tidak diakhiri oleh tanda titik. Misalnya:

- rapim : Rapat Pimpinan

- $\quad$ rudal : Peluru Kendali

Berdasarkan penjelasan beberapa para ahli mengenai bentuk akronim, maka untuk menjawab rumusan masalah pertama, penulis menggunakan teori Tarigan (1993:172).

\section{Makna akronim}

Makna yang muncul dalam akronim sangat terbatas, keterbatasan itu disebabkan oleh akronim itu sendiri yang tidak bisa fleksibel untuk diulang (Sampurno, 1995:257). Makna akronim adalah arti kata sebenarnya yang terkandung dalam suatu kata (Wirjosoedarmo, 1992:22). Misalnya ABRI akronimnya adalah Angkatan Bersenjata Republik Indonesia, sedangkan maknanya adalah pasukan atau prajurit yang menjaga negeri ini dari ancaman musuh, STKIP akronimnya adalah Sekolah Tinggi Keguruan Dan Ilmu Pendidikan, maknanya adalah Sebuah lembaga pendidikan formal yang mencetak calon sarjana dengan berbagai disiplin ilmu dengan jurusannya masing-masing untuk menjadi tenaga pendidik yang professional.

Pemberian makna dapat dibentuk lewat penyempitan dan peluasan makna kata yang lazim dan yang tidak lazim. Artinya, kata itu dikurangi atau ditambah jangkauan maknanya sehingga penerapannya menjadi lebih sempit atau lebih luas (Departemen Pendidikan Nasional, 2006:39). Berdasarkan uraian di atas dapat disimpulkan bahwa makna akronim adalah makna atau sebenarnya yang terkandung dalam kata. 


\section{Fungsi akronim}

Fungsi akronim tidak lebih dari singkatan, sehingga pada akhir-akhir ini fungsi tersebut mengalami perluasan. Akronim bisa digunakan sebagai penyingkat frase atau nama, semboyan, dan media humor. Adapun beberapa fungsi akronim menurut Kridalaksana dalam Sampurno (1995:251-252), yaitu:

a. Akronim sebagai penyingkat frase atau nama

b. Akronim sebagai semboyan dan media humor

\section{Metodologi}

a. Lokasi dan Waktu Penelitian

Penelitian yang dilakukan oleh penulis mengambil lokasi di salah satu basecamp komunitas motor tersebut di kabupaten Merauke, Provinsi Papua. Lamanya waktu penelitian ini sekitar dua bulan.

b. Metode Penelitian

Metode penelitian yang digunakan adalah penelitian kualitatif karena ini merupakan jenis penelitian naturalistik dan penelitiannya dilakukan dalam kondisi alamiah dan menghasilkan data deskriptif berupa ucapan atau tulisan pada perilaku orang-orang yang diamati.

c. Sumber Data

Data yang digunakan dalam penelitian ini bersumber dari anggota komunitas motor di kotaMerauke.

d. Teknik Pengumpulan Data

Dalam pengumpulan data, penulis melakukan wawancara dengan informan untuk mengumpulkan data, dan juga semua tuturan akronim yang dilakukan oleh anggota komunitas tersebut baik lisan maupun tulisan. Setelah itu penulis mencatat hasil data untuk selanjutnya diidentifikasi dan dianalisis berdasarkan teori yang ada.

e. Analisis Data

Data yang dikumpulkan dianalisis dengan menggunakan teori akronim menurut Tarigan dan Sampurno. 


\section{Pembahasan}

\section{Bentuk dan Makna Akronim}

Bentuk akronim dalam komnunitas motor di kota Merauke beserta maknanya terdiri dari, akronim bentuk huruf awal kata, bentuk suku kata, bentuk huruf awal dan suku kata, dan bentuk frase.

\section{a) Akronim Berbentuk Huruf Awal Kata}

Akronim ini dihasilkan dengan pengambilan huruf-huruf awal pada setiap kata seperti contoh di bawah ini:

- MMC $\leftarrow$ Motor Matic Club :

'sebuah club khusus untuk motor matic'

Contoh: kam anana MMC toh?

(kamu anak-anak MMC kan?)

- $\quad$ ATM $\leftarrow$ Aku Tayang Moneymu :

'ditujukan kepada cewek atau cowok yang matre'

Contoh: kam stop pacar deng perem-perem ATM dorang tu.

(kamu stop pacaran dengan perempuan-perempuan ATM itu)

- OTW $\leftarrow$ On The Way :

'dalam perjalanan menuju suatu tempat yang dituju'

Contoh: sa $\boldsymbol{O T W}$ bengkel ni.

(saya OTW bengkel sekarang)

- $\quad$ MC $\leftarrow$ Mio Club :

'sebuah club khusus untuk motor matic yang bermerek Mio keluaran Yamaha'

Contoh: kam sudah nih yang dong bilang MC?

( kalian ini yang mereka bilang Mio Club)

- $\quad$ BBM $\leftarrow$ Bahan Bakar Mahal :

'BBM juga memiliki akronim dari 'bahan bakar minyak' yang bermakna bahan bakar berupa minyak tanah, bensin, solar, dan lain-lain, tetapi yang dimaksudkan dalam hal ini adalah harga bahan bakar sedang mengalami kenaikan harga'

Contoh: su tau ada BBM baru bajalan trus.

(sudah tau ada BBM tapi jalan-jalan terus)

\section{- HTC $\leftarrow$ Hidup Tanpa Cinta :}


'makna ini mencirikan seorang anggota komunitas motor yang belum pernah pacaran atau seseorang yang selalu tidak memiliki seorang kekasih'

Contoh: tra usah heran lai, dong tu macam HTC kah?

(tidak usah heran lagi, mereka seperti HTC)

\section{b) Akronim Berbentuk Suku Kata/Penggalan Kata.}

Akronim ini dihasilakan dengan pengambilan setiap suku kata seperti contoh di bawah ini:

\section{- Komomesa $\leftarrow \underline{\text { Komunitas Motor Metic Nusantara: }}$}

'ditujukan kepada semua komunitas motor matic yang ada di seluruh Indonesia'.

Contoh: kayaknya komomesa blom talalu top di mroke sini e?

(kayakya komomesa belum terlalu terkenal di kota merauke ya?)

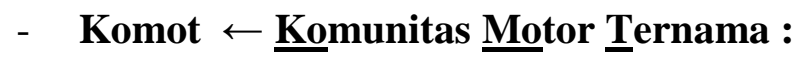

makna ini digunakan untuk kumpulan motor-motor yang bermerek berdasarkan tinggi harga penjualn motor tersebut.

Contoh: kam ni cocok masuk di komot

(kalian ini pantasnya bergabung di komot)

- Bolis $\leftarrow$ Bocah Iblis :

'bolis merupan salah satu bahasa batak yang berarti iblis, tetapi dikarenakan ada salah seorang anggota komunitas yang masih mudah usianya dan sering mengajak anggota lainnya untuk melakukan hal-hal yang tidak diinginkan'

Contoh: dasar bolis ko.

(emang kamu bolis)

\section{- $\quad$ Poster $\leftarrow \underline{\text { Posisi Terakhir : }}$}

'menanyakan keberadaan sesama anggota komunitas motor.'

Contoh: Wan, poster di?

(kawan, posisi terakhir di mana?)

- Laba $\leftarrow$ Lawan Baca :

'menyatakan bahwa lawan bicara sudah mengetahui terlebih dahulu'

Contoh: tra usah bicara bisik-bisik, kam pu rencana tuh laba skali.

(tidak usah berbisik-bisik, kamu punya rencana laba)

- Polisi $\leftarrow$ Polo Langsung Isi : 
'Ini juga termasuk bentuk kata yang mempunyai makna dari polisi adalah anggota badan pemerintah yang bertugas menjaga keamanan dan ketertiban umum, tetapi makna ini ditujukan untuk kepada seorang lelaki playboy dalam anggota komunitas motor yang setiap punya gebetan baru langsung diajak kencan. Makna ini sedikit vulgar dikarenakan baru kenal dengan seorang wanita langsung diajak tidur'.

Contoh: Ko baru kenal perem saja langsug su polisi?

(Kamu baru kenalan dengan cewek saja langsung sudah polisi?)

\section{- Golkar $\leftarrow$ Golongan Kaya (penuh) Rencana :}

'seseorang yang selalu memiliki gagasan dalam merencanakan setiap kegiatankegiatan dalam komunitas tersebut'.

Contoh: dong pu geng tu cocok kas nama golkar.

(mereka punya geng itu cocok diberi nama golkar)

\section{c) Akronim Berbentuk Huruf Awal Kata dan Suku Kata}

Akronim ini dihasilkan dengan pengambilan huruf awal kata dan diikuti dengan suku kata seperti contoh di bawah ini:

- Ebuta $\leftarrow$ Emang Buat Apa :

'untuk menanyakan bila diajak oleh seorang teman untuk berpergian atau untuk melakukan sesuatu'.

Contoh: A. Ko mo ikut sa ke bengkel kah ti? ( kamu mau ikut saya ke bengkel atau tidak?)

B. ebuta di sana? (emang ngapain di sana?)

- Ajakan $\leftarrow$ Assal Jangan Kencan :

'maknanya untuk mengigatkan kepada anggota komunitas yang meminjam motor salah seorang temannya, agar mengunakan motor tersebut untuk keperluan yang penting, bukan untuk keperluan yang lain seperti membonceng kekasihnya atau yang lainnya'.

Contoh: ko bisa pinjam, tapi tra ajakan $e$.

(kamu bisa pinjam, tapi tidak ajakan yah.)

- Abuti $\leftarrow$ Abunawas Tinggi :

'seseorang yang suka menipu' 
Contoh: ko stop abuti tong sudah!

(Kamu berhenti menipu kita yah!)

- Epen $\leftarrow$ Emang Penting :

'menyatakan sesuatu hal yang bersifat penting'

Contoh: ko epen kah? (kamu epen kah?)

\section{d) Akronim Berbentuk Frase}

Akronim ini dihasilkan dengan pengambilan dua kata seperti contoh di bawah ini:

\section{- Ijo Tomat $\leftarrow$ Ikatan Jomblo Terhormat :}

'Ditujukan kepada beberapa anggota komunitas motor yang tidak mempunyai kekasih, dan mereka tetap dihormati di antara anggota komunitas lainnya yang sdh menikah maupun yang masih berstatus pacaran'.

Contoh: yang su lama trada pacar itu cocoknya jadi ijo tomat

(yang sudah lama tidak ada pacar itu cocoknya di panggil ijo tomat)

- Mati Sesat $\leftarrow$ Mau Gratisan Setiap Saat :

'ditujukan kepada orang yang suka gratisan'

Contoh: kam slalu mati sesat saja, tra bisa traktir kita kah.

(kalian selalu mati sesat saja, tidak bisa traktir kita yah)

- Botol Kecap $\leftarrow$ Bodoh Tolol Kebanyakan Cakap :

'orang yang bodoh tetapi banyak ngomongnya'

Contoh: anak ini bikin gerakan tambahan padahal botol kecap

( anak ini banyak tingkahnya padahal botol kecap)

- Jojobah Oil $\leftarrow$ Jomblo-Jomblo Bahagia Oke dan Gokil :

'seseorang yang tetapi terlihat bahagia dan selalu ceria walaupun tidak memiliki seorang kekasih'.

Contoh: sa ini kan jojobah oil (saya inikan jojobah oil)

- Duren Sawit $\leftarrow$ Duda Keren Sarang Duit :

'seorang duda tampan yang mempunyai banyak uang'

Contoh: malam ini tong dapa traktir makan dari duren sawit

(malam ini kita semua akan ditraktir makan oleh duren sawit)

Pada hasil penelitian di atas dapat ditemui bahwa untuk akronim yang mengambil awalan huruf maka ditulis dengan huruf kapital semua. sedangkan, yang merupakan 
akronim dari penggalan suku kata maka ditulis dengan huruf kecil, namun diawali dengan huruf kapital. dan juga terdapat temuan bahwa akronim berbentuk frase. bentuk frase ini masing-masing kata ditulis dengan huruf kecil dan diawali dengan huruf kapital. Dan untuk setiap contoh ada bentuk akronim terlihat bahwa akronim berbentuk suku kata yang paling banyak ditemui dan digunakan dalam komunitas motor di kota Merauke.

\section{Fungsi akronim}

Dari waktu ke waktu, akronim semakin mendapat tempat dalam penggunaannya di masyarakat kita. Hal ini bisa terjadi karena ditengarai akronim memiliki beberapa fungsi. Semula fungsi akronim tidak lebih dari singkatan. Pada akhir-akhir ini fungsi tersebut mengalami perluasan. Akronim bisa digunakan sebagai penyingkat frase atau nama, semboyan, dan media humor, dan juga sebagai pembeda asal kata dan makna.

\section{a) Akronim sebagai penyingkat frase atau nama}

Akronim ini dihasilkan dengan mmenyingkat suku kata pertama dan terakhir, dan juga tiap suku kata pertama dari asal kata. Sebagai contoh:

- Matic $\leftarrow$ Machine Automatic :

'mesin secara otomatis'

Contoh: Motor Yamaha matic terbaru de pu harga masih mahal

(Motor Yamaha matic terbaru harganya masih mahal)

\section{- Honda $\leftarrow$ Honor Daerah:}

'ditujukan kepada anggota komunitas motor yang bekerja sebagai pegawai honorer dalam pemerintahan daerah'

Contoh: sa skarang honda di dinas pariwisata

(Saya sekarang honda di kantor dinas pariwisata)

- Jahat $\leftarrow$ Jatuh Hati :

'jatuh cinta kepada seseorang'

Contoh: kitorang pu kawan satu ni de lagi jahat

(kita punya teman lagi jahat)

\section{- Bobi $\leftarrow$ Botak Biadab :}

'orang yang kepalanya botak tapi kelakuannya tidak baik'

Contoh: de pu nama baru skarang bobi 
(dia punya nama terbaru sekarang bobi)

b) Akronim sebagai semboyan dan humor

Fungsi ini untuk menyingkat semboyan atau humor yang asal katanya terlalu panjang. Sebagai contoh:

- Bahenol $\leftarrow$ badan hebat otak nol :

'bodynya gagah tapi otaknya tidak pandai'

Contoh: kam lihat pace bahenol de su datang nih.

(kalian lihat laki-laki bahenol sudah datang)

- Gunawan $\leftarrow$ gundul tapi menawan :

'orang yang kepalanya biar dibotakin tetap menawan'

Contoh: biar ko gunawan, tetap banyak cewek naksir deng koi.

(biar kamu gunawan, tetap masih ada cewek yang suka sama kamu)

- Diadora $\leftarrow$ diam-diam doyan waria :

'secara tersembunyi suka sama kaum waria'

Contoh: anak satu nih kapala diadora

(anak ini masih suka diadora)

- $\quad$ Romusa $\leftarrow$ rombongan muka susah :

'beberapa orang yang terlihat mendapatkan kesusahan'

Contoh: dong cocok masuk dalam romusa

(mereka pantasnya tergabung dalam romusa)

- Beriman $\leftarrow$ bersih, indah, dan aman :

'sebagai slogan dalam dalam komunitas motor'

Contoh: tong pu bascamp ni musti selalu beriman.

(kita punya bascamp harus selalu beriman)

Dari beberapa contoh di atas terdapat satu contoh fungsi pada semboyan yaitu 'beriman', sedangkan yang lainnya merupakan fungsi dari humor. Sehingga terbukti bahwa komunitas ini lebih suka menggunakan akronim sebagai humor.

\section{c) Akronim sebagai pembeda asal kata dan makna}

Fungsi ini dapat dilihat bahwa akronim dari huruf awal kata boleh sama, tetapi mempunyai asal kata dan makna yang berbeda, sebagai contoh:

\section{- BMW $\leftarrow$ Body Menipu Wajah}


'postur tubuh lebih indah dibandingkan wajah seseorang'

- BMW $\leftarrow$ Buat Memikat Wanita

'sesuatu benda atau yang lainnya digunakan agar dapat memikat seorang wanita'

- CLBK $\leftarrow$ Cinta Lama Belum Kelar

'kisah cinta dengan kekasih belum selesai, sudah ada kekasih yang baru. Atau dengan kata lain terjadinya peselingkuhan'

- CLBK $\leftarrow$ Cinta Lama Buang Kelaut

'seorang mantan kekasih yang telah menyakiti hati pasangannya, sehingga kekasih tersebut di darat terus-menerus melakukan hal yang sama kepada orang lain, mending dibuang ke laut'

- CLBK $\leftarrow$ Cinta Lebih Baik Kandas

'hubungan pasangan kekasih yang terus-menerus tidak akur, lebih baik dihentikan daripada diteruskan'

- CLBK $\leftarrow$ Cinta Lama Bersemi Kembali

'kisah percintaan dengan seorang mantan belum selesai karna masih dilanjutkan'

- GALAU $\leftarrow$ God Always Listening And Understanding

'seseorang yang selalu yakin dan percaya bahwa Tuhan selalu memahami dan mendengarkan permintannya.

- GALAU $\leftarrow$ Gue Akan Lakukan Apapun

'seseorang yang rela berbuat apa saja untuk mendapatkan yang dia inginkan'

- GALAU ᄂ Gelisah Antara Lanjut Atau Udahan

'merasa tidak tenang karena sesuatu hubungan asmara yang harus dilanjutkan atau harus dihentikan'

Berdasarkan fungsi akronim di atas terlihat bahwa daya ingat manusia secara universal sangat terbatas. Dengan keterbatasan itu manusia berusaha mencari alternatif termudah dalam mengingat sesuatu yang panjang dengan bantuan bentuk-bentuk pendek. Bentuk pendek itu bisa berupa singkatan, penggalan, kontraksi, lambang huruf, atau akronim. Selain itu juga, akronim dalam humor ini cenderung dimunculkan oleh penutur dalam suasana santai. Akronim tersebut muncul atas dasar tidak sengaja para penutur untuk bercanda dengan teman sebaya. Penutur berusaha membiasa kan kepanjangan akronim yang sudah ada atau menghadirkan akronim baru berdasarkan kata-kata yang ada 
dalam bahasa. Namun terdapat juga fungsi pembeda asal kata dan makna, artinya bahwa akronimnya sama namun asal kata dan maknanya berbeda.

\section{Simpulan}

Dari hasil penelitian dapat disimpulkan bahwa akronim dalam konunitas motor digunakan khusus sehari-hari antar sesama anggota komunitas tersebut. Adapun bentuk akronim dalam penelitian ini yaitu (1) bentuk huruf kata awal; (2) bentuk suku kata; (3) bentuk huruf awal kata dan suku kata; (4) bentuk frase. Selain itu juga fungsi akronim dalam penelitian ini yaitu sebagai penyingkat frase atau nama, sebagai semboyan atau humor, dan sebagai pembeda asal kata dan makna.

Selain itu juga ditemukan kata-kata yang terdapat dalam Kamus Besar Bahasa Indonesia seperti: polisi, jahat, poster, bahenol. Ada juga terdapat afiksasi seperti: 'beriman' dari kata dasar iman, dan 'ajakan' dari kata dasar ajak. Selain itu terdapat nama orang yang dijadikan akronim, seperti: gunawan, dan bobi.

\section{Daftar Pustaka}

Finoza, Lamuddin. 2002. Komposisi Bahasa Indonesia Untuk Mahasiswa Nonjurusan Bahasa. Jakarta : Diksi Insan Mulia.

Husain, Abdul Rajak. 1995. Singkatan dan Akronim Baku Bahasa Indonesia. Solo : Aneka. Kridalaksana, H. (1992). Pembentukan Kata dalam Bahasa Indonesia. Jakarta: Gramedia Pustaka Utama.

O’Grady, William et al. 1992. Contemporary Linguistic Analysis. Toronto: Copp Clark Pitman Ltd.

Parsidi, Agata. 1992. Kamus Akronim Inisialisme dan Singkatan. Jakarta : Pustaka Utama Grafiti.

Sampurno, Adi. 1995. Prasasti Majalah Ilmu Bahasa dan Seni. Surabaya : IKIP Surabaya. Tarigan, Henri Guntur. 1993. Pengajaran Kosakata. Bandung : Angkasa.

Wirjosoedarmo, Soekono. 1992. Tata Bahasa Bahasa Indonesia. Surabaya : Sinar Wijaya. 